\title{
A noção de folksonomia: uma abordagem terminológica
}

\author{
J éssica Câmara Siqueira*
}

\begin{abstract}
The technical-scientific development and the constant change in circumstances affecting the field of Information Science, specialty area of recent creation. Such changes in the area are evident in his terminology, especially with the inclusion of new terms, with emphasis on the creation process of lexical borrowing. Given this finding, we selected a neologism recognized the area, folksonomy, in order to reveal the different perspectives of terminology that support the creation of its name. From the work terminologist analysis and synthesis, it was possible not only to define the character designation of the term, but more deeply understand the nuances of their own field of expertise of Information Science.
\end{abstract}

Keywords: terminology; science information; neologism; lexical borrowing; folksonomy.

Resumo: 0 desenvolvimento técnico-científico e as constantes mudanças conjunturais afetam o domínio da Ciência da Informação, área de especialidade de criação recente. Tais mudanças na área se evidenciam em sua terminologia, principalmente com a inserção de novos termos, com destaque para o processo de criação lexical do empréstimo. Diante de tal constatação, selecionou-se um reconhecido neologismo da área, folksonomia, com o objetivo de desvelar as diferentes perspectivas terminológicas que corroboram a constituição de sua designação. A partir do trabalho terminográfico de análise e síntese foi possível não só delimitar o caráter designativo do termo, mas compreender mais profundamente as nuanças do próprio domínio de especialidade da Ciência da Informação.

Palavras-chave: terminologia; Ciência da Informação; neologismo; empréstimo; folksonomia.

* Doutoranda em Letras pela Universidade de São Paulo, na área de Filologia e Língua Portuguesa. Mestre em Ciência da Informação pela USP. Especialista em Arquivos pela USP. Bolsista Capes. Email: jessica.siqueira@usp.br. 


\section{Introdução}

Em âmbito geral, o estudo da neologia, segundo ALVES (1990), permite verificar as transformações socioculturais de uma língua, refletindo 0 desenvolvimento de uma comunidade discursiva. Já em um domínio de especialidade, em que os conceitos técnicos e científicos não cessam de serem criados, nomeados e renomeados, em razão da dinâmica de transformações conjunturais e tecnológicas, é salutar considerar os estudos neológicos a fim de melhorar a compreensão do caráter identitário dos domínios.

As unidades neológicas podem ser criadas tanto por razões estilísticas como para denominar novas realidades e conceitos, principalmente no escopo dos domínios de especialidade (ALVES 1990).

O termo, no âmbito contemporâneo, deve ser analisado em seus diferentes contextos discursivos, o que Ihe permite encontrar seu valor como uma unidade significativa de uma área na perspectiva do uso, viés que abre espaço aos estudos de variação linguística. Considerando as vertentes contemporâneas da Terminologia, a variação linguística acaba sendo reconhecida como um fenômeno natural, sendo, portanto, passível de ser descrita, categorizada e analisada cientificamente.

Nos estudos terminológicos atuais, com destaque para as vertentes da Teoria Comunicativa da Terminologia (Cabré 1999; Cabré, FreiXa, Solé 2000) e da Socioterminologia (Boulanger 2008; GAUDIN 1993), o termo não deve ficar restrito ao âmbito normativo e monorreferencial como na Terminologia Clássica, influenciada pelos trabalhos de Wüster e Lotte. Assim, enquanto a Terminologia Clássica enfatizava a separação entre a língua e a linguagem especializada, diferenciando palavra e termo, as novas perspectivas terminológicas percebem que a Terminologia não existe per si, ou seja, se configura em função do uso de uma unidade lexical em um contexto expressivo e situacional determinado (MACIEL 2001). 
Nesse viés, segundo LARA (2006), a principal contribuição da Terminologia não é apenas a mera identificação dos termos, mas a "validação social das escolhas de forma e de conteúdo, como expressão pragmática da observação dos discursos das comunidades de uso". Dessa forma, as estruturas de organização da informação reproduzem os contextos histórico-culturais e suas transformações no tempo e no espaço (LARA 2006).

Os termos dos domínios de especialidade, por ser um subconjunto da língua geral, assim como ela, estão sujeitos à variação no tempo/espaço, já que refletem as diferentes necessidades e motivações de uma comunidade discursiva. Além disso, com o desenvolvimento técnico-científico e as constantes mudanças conjunturais, nota-se 0 aparecimento de novos termos nas áreas de especialidade. Segundo ALVES (2006), esses novos termos surgem, antes de tudo, para denominar os novos inventos e tecnologias, com função de renovação lexical, o que ela denomina como neologia terminológica, principalmente encontrada nos processos vernaculares de derivação, composição, transferência semântica, formações sintagmáticas, redução e pelo empréstimo de outros idiomas.

Considerando o domínio de especialidade da Ciência da Informação, área ainda nova e em constante incorporação terminológica, foi selecionado para análise o termo folksonomia. A seleção do termo foi motivada por dois aspectos: primeiro por ser um neologismo, que ratifica o caráter dinâmico da área, que em recorrência da influência tecnológica incorpora vários termos estrangeiros para sua constituição; e segundo por ser um termo que mesmo reconhecidamente utilizado pela área ainda não possui uma delimitação conceitual, o que permite uma análise terminológica mais acurada.

O objetivo do trabalho foi identificar os contextos de formação do termo folksonomia, procurando desvelar, a partir da análise terminológica, a noção mais próxima para sua designação. Para isso, foi utilizada para a coleta dos contextos a Base de Revistas da área da Ciência da Informação (BRAPCI), repositório digital com publicações desde a década de 1970. Depois de selecionados os contextos nos quais surge o neologismo folksonomia foi feita a 
análise e a síntese de suas designações, com auxílio da ferramenta de mapa conceitual. Por fim, com o mapa de suas principais designações está apresentada a síntese de sua noção conceitual.

\section{Os estudos neológicos}

A noção de neologia remonta o grego neo (novo) e logos (discurso). A partir da decodificação etimológica do termo chegamos à noção genérica de "um estudo do novo", ou seja, o estudo de princípios e métodos de criação de novas palavras (BOULANGER 2008).

Segundo CABRÉ (1999), para que uma unidade lexical seja considerada neologismo, devem ser observados alguns aspectos:

- Critério temporal - aparição recente da palavra no léxico.

- Critério lexicográfico - ausência da palavra em dicionários, já que a presença em dicionários é uma marca para identidade da unidade lexical de uma língua.

- Critério da instabilidade formal e semântica da palavra.

- Critério da recepção social - o termo deve ter caráter de novidade percebido pelos falantes de uma comunidade discursiva.

Sob o último aspecto é importante ressaltar que a criação lexical é facultada aos membros de uma determinada comunidade discursiva, ou seja, não basta que um neologismo seja criado para ser incorporado a um acervo lexical, já que é a comunidade linguística que valida sua integração para formar um vocabulário. Além disso, também influenciam para tal escolha, fatores extralinguísticos (tendências políticas, econômicas e socioculturais), assim como o papel das comunicações de massa e das obras literárias (ALVES 1990).

Dessa forma, o caráter neológico de um termo é relativo e arbitrário, já que depende de um corpus de exclusão (dicionários ou vocabulários 
especializados), cujos elementos serão por definição considerados conhecidos (REY 1979).

Assim, pode-se dizer genericamente que uma palavra é considerada neologismo se é uma unidade lexical de ciclo de vida recente ou emprestada de outro código linguístico. No primeiro caso, podem ser denominados como neologismos autóctones ou formais, aqueles criados pelos processos de derivação, composição, redução de palavras ou mudança do caráter semântico, quando os termos "ganham" outro significado em determinados contextos. Já no caso de empréstimo ocorre a adoção do termo estrangeiro, tanto por meio da importação, quando a unidade lexical permanece inalterável no código linguístico que se incorpora, ou pela substituição, quando o termo é substituído por outro, fazendo-se as devidas adaptações fonológicas, lexicais e semânticas (BOULANGER 2008).

Os neologismos autóctones são desenvolvidos a partir de aspectos fonológicos, morfológicos e semânticos do próprio código linguístico, enquanto o empréstimo "adota" ou "adapta" o termo estrangeiro à língua. Um termo estrangeiro geralmente é adotado em outra língua quando se percebe uma lacuna ou inadaptação para se nomear algo. Nesse caso ocorre, portanto, uma tentativa de se reproduzir com modelos disponíveis na língua uma representação do termo estrangeiro (CARVALHO 2009).

No caso dos empréstimos por substituição, recorre-se ao aparato de elementos mórficos e fonológicos da língua para se fazer as adequações do termo ao código linguístico. A substituição pode manifestar-se em diferentes níveis. Segundo CRYStal (1985 apud CARvalho 2009) podem ser classificadas as seguintes tipologias de substituição:

- Loanwords - importação de forma e significado com adaptações do sistema fonológico. Ex.: leiaute.

- Loanblends - o significado é adotado, mas apenas parte da forma é da língua fonte. Ex.: barrashophing.

- Loanship - o significado é importado, mas a forma é nativa. Ex.: deletar. 
SIQUEIRA, J. C. A noção de folksonomia: uma abordagem terminológica

- Loan translations - a tradução é feita item por item. Ex.: skyscrapper (arranha-céu). (CRYSTAL 1985 apud CARVAlHO 2009: 76)

Há também a denominação dada por GUILBERT (1975), que opta por diferenciar a noção de empréstimo e estrangeirismo. 0 estrangeirismo estaria atrelado aos nomes próprios, patronímicos e termos que trazem em seu bojo realidades culturais que não encontram correspondência na língua receptora. O empréstimo, por sua vez, seria referente ao termo que já foi integrado ao sistema linguístico. A fase neológica, portanto, corresponderia ao período intermediário entre o estrangeirismo e o empréstimo, momento denominado pelo autor como peregrinismo (GUILBERT 1975).

Nessa fase de peregrinismo, em que o termo está se "adaptando" a um novo código linguístico, devem ser observados os critérios morfossintáticos, semânticos e fonológicos para sua integração. No primeiro caso, essa integração é possível se o termo estrangeiro está suscetível às adequações morfossintáticas da outra língua, demarcadas pelos processos de derivação, composição, marcações de gênero, número ou mesmo a categoria gramatical. Quanto ao critério semântico, percebe-se a instalação de um novo termo na língua receptora quando este não se restringe a um significado, ganhando traços de polissemia. Já o último critério é percebido quando ocorre uma integração do termo estrangeiro, ao adaptar-se aos fonemas da língua receptora, fato que muitas vezes é posterior à integração ortográfica do termo (ALVES 1984).

Além dos critérios anteriormente descritos, vale lembrar que 0 neologismo não é um elemento isolado, ou seja, é parte do sistema dinâmico da língua; logo, não pode ter seu valor delimitado per si, mas percebido em relação aos demais termos da língua, os quais se relaciona. Dessa forma, percebe-se que somados aos critérios expostos há ainda a necessidade do termo estrangeiro ser aceito por uma comunidade linguística. Tal fenômeno de aceitabilidade social geralmente é percebido pela frequência de uso e pelo registro do termo em obras lexicográficas (ALVES 1984). 
De forma geral, uma palavra passa por cinco estágios de vida: 0 neológico, marcado pela instabilidade e novidade; a recepção social, quando seu uso se torna mais frequente e é aceito por uma comunidade linguística, tendo como marco de aceitação o registro em obra lexicográfica; o envelhecimento, quando mesmo ainda ativo, sua frequência de uso diminui; a obsolescência, quando ocorre o uso passivo do termo, já até sendo marcado nas obras lexicográficas seu desuso; e por fim, quando cai em desuso e é retirado do dicionário (BOULANGER 2008).

\section{O neologismo folksonomia}

O neologismo folksonomia é proveniente do inglês folksonomy, termo cunhado por Thomas Vander Wal, arquiteto da informação em 2004, para designar o fenômeno de atribuição livre e pessoal, de etiquetas aos conteúdos informacionais disponibilizados na web, a fim de facilitar a recuperação da informação. Segundo Wal, a ideia veio da sugestão de outro autor, Eric Scheld, que denominou o mesmo fenômeno como folk classifiction. Wal aproveitou o primeiro termo, conservando a noção de "pessoas", mas agregou outro afixo "-nomy", proveniente do termo taxonomy. Essa escolha não é aleatória, já que o termo taxonomia diz respeito a um tipo de classificação hierárquica, formal e categórica. Contudo, tal classificação é de caráter oposto ao observado na folksonomia, já que as pessoas, com todas as suas singularidades de formação e perspectivas de enxergarem 0 mundo, estabelecem seu "recorte de realidade" para determinado contexto, usando para isso rótulos que sintetizam sua ideia de determinado assunto (BRANDT, MEDEIROS 2010).

Como o termo ainda está em fase de peregrinismo, ou seja, transição entre o estrangeirismo e o empréstimo, está vulnerável às adaptações linguísticas, antes de integrar-se totalmente. Nesse período, segundo GUIBERT 
(1975), adotam-se três critérios para delimitar o período de integração a língua: 0 aspecto morfossintático, o semântico e o fonológico.

No aspecto fonológico, para que um termo se integre a outro idioma deve adaptar-se ao sistema fonemático da língua receptora. E a identificação dessa adaptação pode ser visualizada através da ortografia, onde é feita a devida adequação da representação sonora de um idioma para outro (GUILBERT 1975). No caso de folksonomia observa-se que ocorre tal adaptação principalmente marcada pela terminação, optando-se pela versão de "-nomy" para a forma aportuguesada do sufixo "-nomia". Contudo, há casos em que mesmo utilizando-se uma versão fonemática do idioma receptor, ainda prefere-se utilizar a grafia totalmente estrangeira, a exemplo de bouquet (ALVES 1984).

No aspecto morfossintático, o lexema estrangeiro deve estar suscetível à derivação ou à composição da outra língua (GUILBERT 1975). No caso do termo folksonomia, pode-se verificar que é formado a partir de uma base em inglês, folk-, e uma lexia que tem um correspondente em português, -nomy traduzida em "-nomia", lexia comumente encontrada em português para tratar áreas do conhecimento (Astronomia, Biblioteconomia, Economia etc.). Podemos também considerar que a lexia "-nomia" se subdivide em "nom-", sintagma proveniente de "nomear", designação que incorpora o valor denominativo que o termo possui, e o sufixo "-ia", utilizado tanto para áreas do conhecimento, como para profissionais e suas funções.

Outros aspectos a serem lembrados no âmbito morfossintático são quanto à categoria gramatical, gênero e número. Nos três casos, observa-se que o estrangeirismo ao se integrar ao outro idioma, via de regra, permanece na mesma categoria gramatical: substantivo, em sua maioria, gênero e número semelhantes. 0 termo folksonomia não foge a esse padrão (ALVES 1984).

Outro aspecto que também está no âmbito morfossintático é o decalque. Se fosse feito um decalque do termo, ou seja, uma tradução literal, teríamos a essência de seu significado, mas ainda não seria uma expressão 
completa e abrangente para as diferentes nuanças de significado pelas quais 0 termo assimilou (ALVES 1984). No decalque, teríamos a seguinte versão para folksonomia: denominação (nomy) dada por pessoas (folk). Contudo, no trabalho terminológico realizado, observou-se que essa designação apenas revela uma faceta semântica do termo, que para área da Ciência da Informação "ganha" contornos polissêmicos. Esse aspecto de polissemia, portanto, ratifica o critério semântico.

Tendo como base esses critérios de designação do neologismo folksomia, analisaremos a partir da metodologia terminológica os diferentes contextos em que o termo é utilizado na área. Para isso foram coletados contextos de artigos de periódicos da área disponibilizados na Base Referencial de Revistas da área de Ciência da Informação (BRAPCl), produzidos entre 2007 a 2012.

Esse recorte temporal justifica-se, pois anterior a essa data o termo não aparecia em revistas da área, no Brasil. Ao todo, o termo apareceu em 17 artigos como palavra-chave, ou seja, considerado pelos autores um dos termos centrais da pesquisa, não sendo contabilizadas aqui as vezes que 0 termo aparece de modo secundário ou meramente referencial, já que o intuito foi reconhecer traços que pudessem evidenciar sua designação para a área.

\section{Análise terminológica do termo folksonomia}

A coleta dos contextos referentes ao conceito de folksonomia foi feita observando-se traços definicionais, descritivos e funcionais do termo aplicado à área. Com o auxílio das tabelas de análise e síntese foi possível verificar os 17 contextos subdivididos em seus principais traços.

A seguir, um modelo da tabela utilizada para análise dos contextos: 
SIQUEIRA, J. C. A noção de folksonomia: uma abordagem terminológica

\begin{tabular}{|c|c|c|c|c|}
\hline $\begin{array}{l}\text { "Pode ser } \\
\text { definida como } \\
\text { um sistema de } \\
\text { organização da } \\
\text { informação ou } \\
\text { categorização } \\
\text { social, } \\
\text { bottom-up, ou } \\
\text { seja, de } \\
\text { muitos para } \\
\text { muitos [...]". }\end{array}$ & $\begin{array}{l}\text { "Pode ser definida } \\
\text { como um sistema } \\
\text { de organização da } \\
\text { informação [...]." }\end{array}$ & $\begin{array}{l}\text { "[...] } \\
\text { categorização } \\
\text { social }[\ldots] \text { ". }\end{array}$ & $\begin{array}{l}\text { "[...] bottom-up, } \\
\text { ou seja, de } \\
\text { muitos para } \\
\text { muitos }[\ldots] " .\end{array}$ & 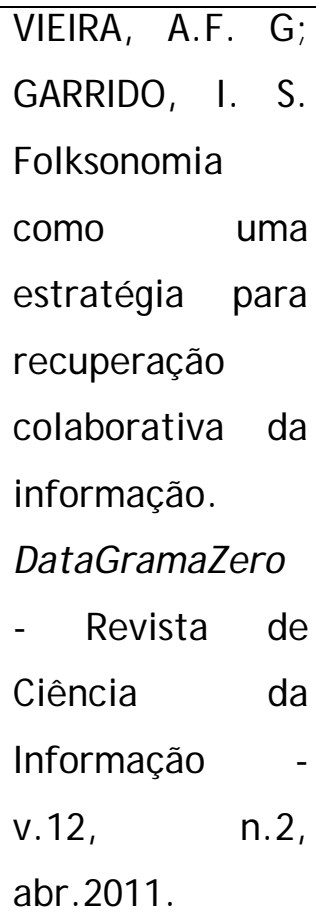 \\
\hline
\end{tabular}

Tabela 1 - Análise terminológica do termo folksonomia.

Fonte: elaboração própria.

$\mathrm{Na}$ análise dos contextos foi observada uma variedade de designações para o termo folksonomia, o que confirma um caráter polissêmico e instável do termo, ainda em processo de peregrinação. Essas distinções eram tanto de natureza morfossintática como semântica. No primeiro caso pode-se citar 0 exemplo do sinônimo "tags afetivas". A lexia composta, ao contrário do esperado, não é formada por sintagmas da língua receptora, mas utiliza de outro termo estrangeiro como lexia principal, por causa de seu caráter substantivo e emprega-se como um adjetivo na língua receptora.

Outro tipo de recorrência, no âmbito morfossintático, é a presença do sufixo "-agem", em alguns traços designativos das funções do termo. Tal sufixo não é escolhido aleatoriamente, pois está relacionado à ideia de ação, movimento, noção que está implícita na formação sintagmática das lexias compostas, a exemplo de: "filtragem colaborativa"; "etiquetagem para recuperação da informação"; "rotulagem colaborativa".

Quanto ao aspecto semântico, a variedade de escolhas designacionais está relacionada principalmente às questões ideológicas de cada autor, que 
mesmo sendo de uma área comum desvelam em seu texto sua perspectiva de encarar a própria área. Um exemplo dessa escolha ideológica pode ser encontrado observando-se dois autores. Enquanto um opta por colocar como expressão sinonímica de folksonomia como "classificação" ou "categorização social", claramente uma escolha embasada nos parâmetros mais tradicionais da representação do conhecimento; outro autor opta por "rede de tags" ou "rede de produção colaborativa", evidentemente uma escolha que considera o contexto mais dinâmico e multifacetado da pós-modernidade.

Além dessas designações houve ainda a seleção de sinônimos para 0 termo utilizando-se de outros estrangeiros, a partir do critério da analogia, ou seja, não correspondiam diretamente à noção de folksonomia, mas permeavam o mesmo campo semântico e até com funções similares. Como exemplos, pode-se citar o "tagging literacy", ou "collaborative tagging", por exemplo.

Diante de tais distinções e diversidade de traços foi feita a síntese das noções do termo. Nessa etapa, para auxiliar a visualização dos principais traços identificados, bem como estabelecer suas relações, foi feito um mapa conceitual, que pode ser visualizado a seguir: 
SIQUEIRA, J. C. A noção de folksonomia: uma abordagem terminológica

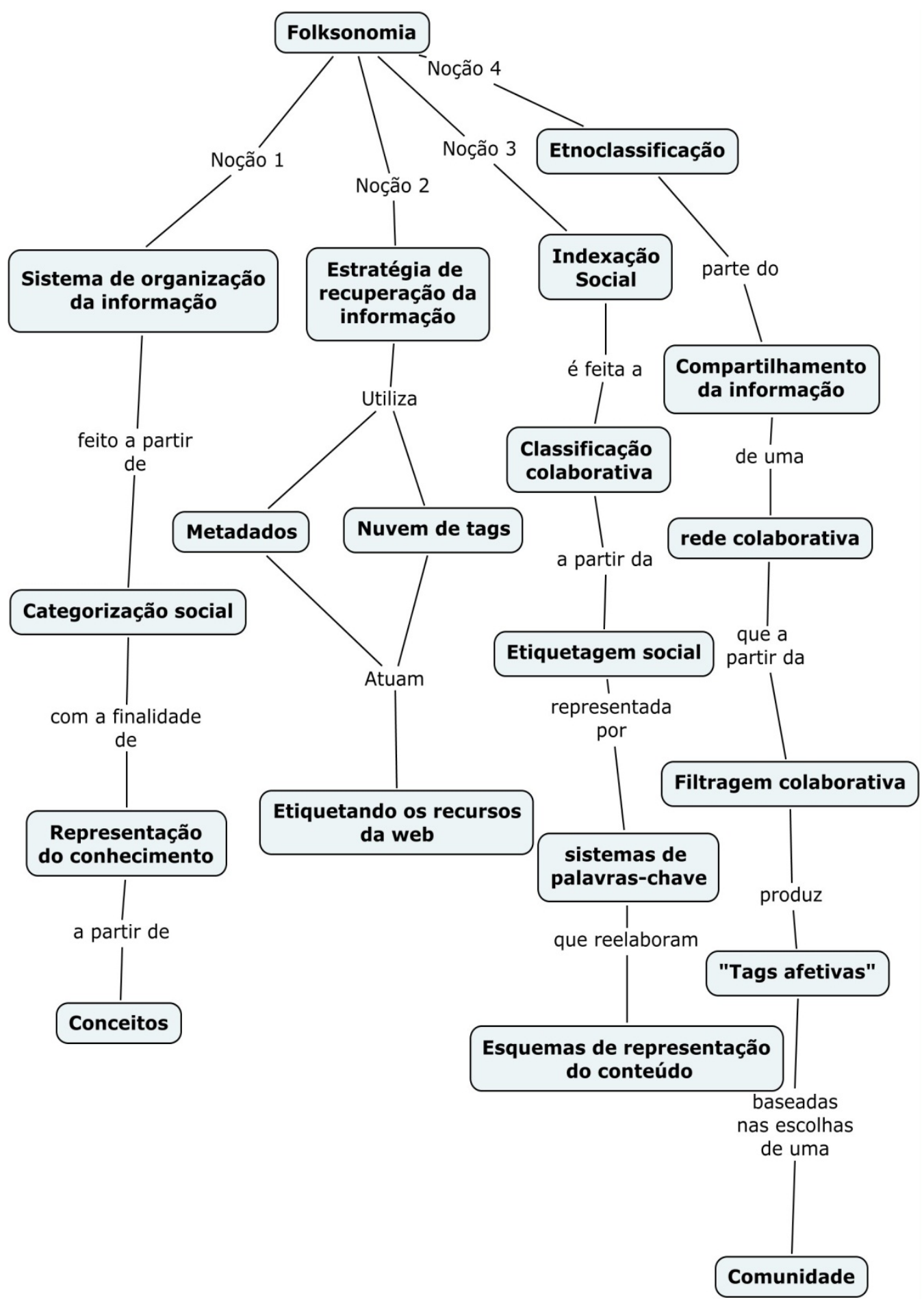

Figura 1 - Mapa conceitual do termo folksonomia.

Fonte: elaboração própria.

Ao observamos o mapa conceitual exemplificado, antes de tudo, constatamos que dentre as definições apresentadas, foi possível delimitar quatro principais noções do termo folksonomia. Tais designações sintetizam o 
arcabouço de traços e funções analisados no processo terminográfico. Além disso, pode-se averiguar que a escolha dos termos traz em seu bojo mais do que as especificações do domínio da Ciência da Informação, desvela a postura política e ideológica dos autores diante da área.

$\mathrm{Na}$ designação de folksonomia como sinônimo de "sistema de organização da informação", resgata-se o arcabouço teórico sobre a organização do conhecimento proposta por HJ ORLAND (2008), além dos estudos de DALBERG (1992) sobre a teoria do conceito. o conceito é importante, pois, a partir dele é possível representar uma ideia sintetizada em um termo. Nessa perspectiva em que parte-se da organização do conhecimento, a base para toda a categorização social é o conceito. Primeiro em um nível individual, refletindo a visão de mundo e as perspectivas de cada indivíduo, e depois a integração desses diferentes olhares constitui um sistema.

Em relação aos outros esquemas de representação do conhecimento, a exemplo dos tesauros e taxonomia, a folksonomia é construída a posteriori, ou seja, primeiro se classificam os objetos informacionais, e depois é que efetivamente "surge" a folksonomia. Nas outras ferramentas, o objeto informacional é classificado apenas se já existem termos para representá-lo.

Outra noção observada foi a folksonomia como uma estratégia de recuperação da informação. Diferente do caso anterior, que parte de uma perspectiva mais subjetiva, pois se escolhe como ponto de partida o conceito, nessa abordagem opta-se por encarar a folksonomia em um viés mais pragmático. Nessa concepção do termo parte-se do objetivo final, a recuperação da informação usando para isso das ferramentas disponíveis na web, metadados e as nuvens de tags, para a realização da etiquetagem. Para alguns autores, essa noção de etiquetagem social (social tagging) é diferente da folksonomia. TALJA (2002) afirma que no primeiro caso, a etiquetagem estaria focalizada no processo de indexação colaborativa, enquanto que a folksonomia propriamente dita estaria relacionada ao sistema de organização do conhecimento. 
Outros autores, optando por uma vertente mais aplicada ou até mesmo operacional do termo, definem simplesmente a folksonomia como uma "indexação social ou colaborativa". Nesse viés, utiliza-se como parâmetro o processo de indexação, operação de classificação temática de um assunto que, aqui, diferente de seu uso formal na área de Ciência da Informação, é feito colaborativamente a partir da delimitação de conteúdos em palavraschave, que terão o papel de representar determinado conteúdo e servir de instrumento para a recuperação da informação.

Por último, a noção de "etnoclassificação", outro neologismo para explicar a noção de folksonomia. Nesse caso, poderíamos dizer que até se aproxima de um decalque, já que o primeiro sintagma "etno" refere-se a um grupo de determinada origem e costumes comuns, noção que se aproxima do sintagma "folk-". Já a segunda parte do termo, "classificação", também está diretamente relacionada ao sintagma "-sonomy", proveniente do termo taxonomia, um tipo de classificação hierárquica. Contudo, o que difere 0 neologismo folksonomia de seu provável decalque, é que em etnoclassificação, há uma referência mais genérica no que diz respeito à organização do conhecimento, definida apenas como "classificação", e não como um tipo específico de classificação, a taxonomia. Nesse caso, o decalque estaria mais próximo da noção pela qual o suposto autor do termo ambicionava, já que as classificações estabelecidas não são formalizadas por padrões hierárquicos ou associativos, como se observam nas categorizações taxonômicas.

Outro aspecto do possível decalque é o sintagma "etno-", que ao contrário de "folk-", mesmo trazendo em sua essência a ideia de povo, traz embrenhado em sua carga etimológica a noção de cultura e identidade, traços que não aparecem no sintagma "folk-", que possui um âmbito mais genérico. Tais considerações nos fazem perceber que a expressão "etnoclassificação" também não é um decalque de folksonomia, pois não se limita a uma mera tradução do termo, já que acrescenta significados que não estão presentes no termo original. 
Na perspectiva da folksonomia como etnoclassificação evidencia-se 0 papel do sujeito no processo de classificação, feita a partir de uma rede colaborativa de indivíduos que produzem e consomem produtos informativos comuns e que interligados em um espaço comum na web fazem a filtragem de conteúdos que acreditam ser relevantes, sintetizando-os em tags afetivas, ou seja, escolhidas a partir de critérios não formais. Nessa seleção é interessante pontuar que a escolha de um termo para pertencer à determinada rede colaborativa é fruto tanto de traços pessoais, já que cada indivíduo possui suas idiossincrasias, quanto a sua formação, hábitos de vida, ou mesmo perspectiva de enxergar o mundo, mas também está arraigada indiretamente aos interesses e a visão de mundo de determinada comunidade.

\section{Considerações finais}

A diversidade de traços e as designações do neologismo folksonomia permitiu que se constatasse que o termo ainda não se integrou totalmente à área da Ciência da Informação, já que apresenta evidências de instabilidade semântica. Somado a isso, somente parte de sua composição, o afixo, se integrou a língua, já que ainda permanece com o radical do sintagma estrangeiro. Outro ponto a ser observado é quanto a sua frequência, que tem se tornado evidente nos últimos cinco anos, pois até então não era mencionado em artigos da área no Brasil, mesmo tendo sido cunhado em 2004.

$\mathrm{Na}$ análise terminológica constataram-se quatro principais noções para o neologismo: "sistema de organização da informação"; "estratégia de recuperação da informação"; "indexação social" e "etnoclassificação". A diversidade de perspectivas para a delimitação do termo evidencia 0 peregrinismo do termo no sistema linguístico, já que ainda não foi adaptado ao idioma, apesar da incorporação do sufixo "-ia" ser um primeiro passo. Além disso, apesar do entendimento da noção de folksonomia para a área da 
Ciência da Informação, ainda não se chegou a um consenso terminológico para sua adaptação ao idioma.

Quanto às designações identificadas observou-se, além do caráter neológico da instabilidade semântica, a escolha ideológica de cada autor pela delimitação designativa do termo. Nessa escolha foi possível observar como os especialistas encaram as mudanças da área, e como um termo como este, proveniente de uma associação histórico-social e de caráter funcional pode ajudar a desvelar a perspectiva que está sendo construída sobre a própria área.

\section{Referências bibliográficas}

ALVES, I. A integração dos neologismos por empréstimo ao léxico português. Alfa, n. 28, São Paulo, 1984, pp. 19-126.

Alves, I. Neologismo. Criação lexical. São Paulo: Ática, 1990.

ALVES, I. M. A renovação lexical nos domínios de especialidade. Ciência e Cultura. v. 58, n. 2, São Paulo abr/ jun, 2006.

BOUlANGeR, J. C. Presentation: images et parcours de la socioterminologie. Méta, 40, n. 2, 1995, pp. 194-205.

BrandT, M.; MedelRos, M. B. B. Folksonomia: esquema de representação do conhecimento? Transinformação, v. 22, n. 2, Campinas, mai/ago, 2010, p. 111-121. Disponível em: «ttp:// revistas. puccampinas. edu. br/transinfo/ viewissue. php?id=25>. (01/ 04/ 2012).

BRAPCl - Base de Revistas da área da Ciência da Informação. Curitiba: Universidade Federal do Paraná, 2012. Disponível em: \ttp:// www. brapci. ufpr. br/ >. (01/ 03/ 2012).

CABRÉ, M.T. La terminología: representación y comunicación. Barcelona: IULAUPF, 1999.

CABRE, M. T. La neologia con a mesura de la vitalitat interna de lês llengues. En: CAbre, M. T.; FreixA, J.; Sole, E. La neologia en el tombant de segle. Barcelona: Institut Universitari de Linguistica Aplicada, Universitat Pompeu Fabra, 2000.

Carvalho, N.M. Empréstimos linguísticos e identidade cultura. In: ALveS, I.M [et al.] Estudos lexicais em diferentes perspectivas [recurso eletrônico]. São Paulo: FFLCH/ USP, 2009. 
DAHLBERG, I. Ethics and knowledge organization: in memory of Dr. S. R. Ranganathan in his centenary year. International Classification, v. 19, n. 1, Frankfurt , 1992, pp. 1-2.

HJ ØRLAND, B. What is knowledge organization (KO)? Knowledge Organization, Würzburg, v. 35, n. 2/3, 2008, pp. 86-101.

LARA, M. L. G. Novas relações entre Terminologia e Ciência da Informação na perspectiva de um conceito contemporâneo da informação. DataGramaZero: Revista de Ciência da Informação, v.7, n.4, ago. 2006.

MACIEL, A. M. B., Quais são os termos da terminologia no século XXI. In: Oliveira, A. M. P. P.; Isquerdo, A. N. (org.) Ciências do léxico: Lexicologia, Lexicografia e Terminologia. 2a ed.Campo Grande: Editora UFMS, 2001.

GUILBERT, L. La créativité lexicale. Paris: Larousse, 1975.

REY, A. La Terminologie: noms et notions. Paris: Presses Universitaires de France, 1979.

TALJA, S. Information sharing in academic communities: Types and levels of collaboration in information seeking and use. In: PennState, EUA, $2002 . \quad$ Disponível em: $\varangle$ http:// citeseerx. ist. psu. edu/ viewdoc/ summary?doi=10.1.1.96.163 >. (01/ 04/2012). 